\title{
EPIGALLOCATECHIN GALLATE TO IMPROVE COGNITIVE AND BEHAVIORAL PERFORMANCE IN CHILDREN WITH FETAL ALCOHOL SYNDROME (FAS)
}

C. Borràs-Novell, A. Herranz Barbero, J. Clotet Caba, O. Garcia-Algar, M. Astals-Vizcaino, V. Andreu-Fernandez Neonatology Department. Hospital Clínic. BCNatal. Barcelona-Spain

\section{Introduction}

Catalonia shows a FAS' prevalence of $51 \%$ in adopted children from East European Countries. Epigallocatechin Gallate is an antioxidant obtained from green tea that acts as a neural plasticity modulator and has been useful in some neurodevelopmental diseases.

Our aims are to determine the efficacy of EGCG as a therapeutic tool for the improvement of cognitive and behavioral performance in patients with FAS .

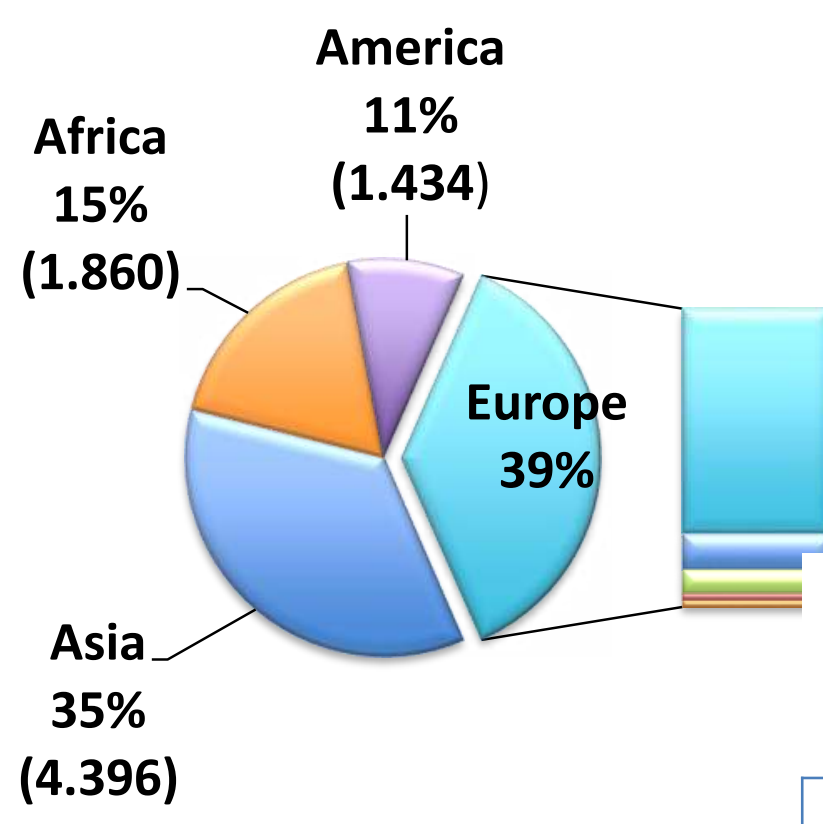

\begin{tabular}{|lll|}
\hline & 1 1r-5th & \\
\cline { 2 - 3 } $\begin{array}{l}\text { Treatment } \\
\text { period } \\
\text { (month) }\end{array}$ & 6 th & 8 \\
\cline { 2 - 4 } & 7-11th & 8 \\
\cline { 2 - 4 } & 12 th & 8
\end{tabular}

\section{Results}

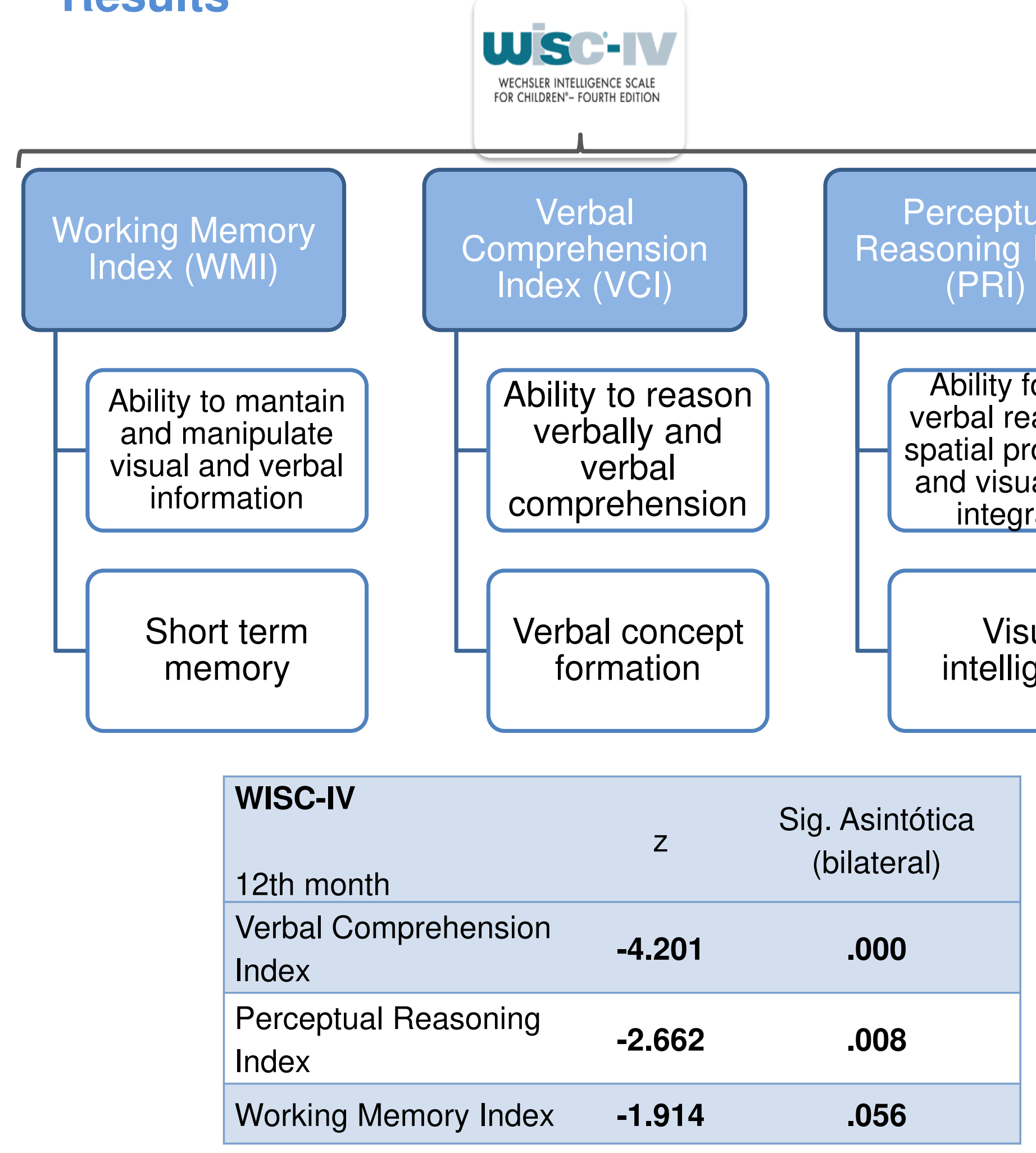

\section{Conclusions}
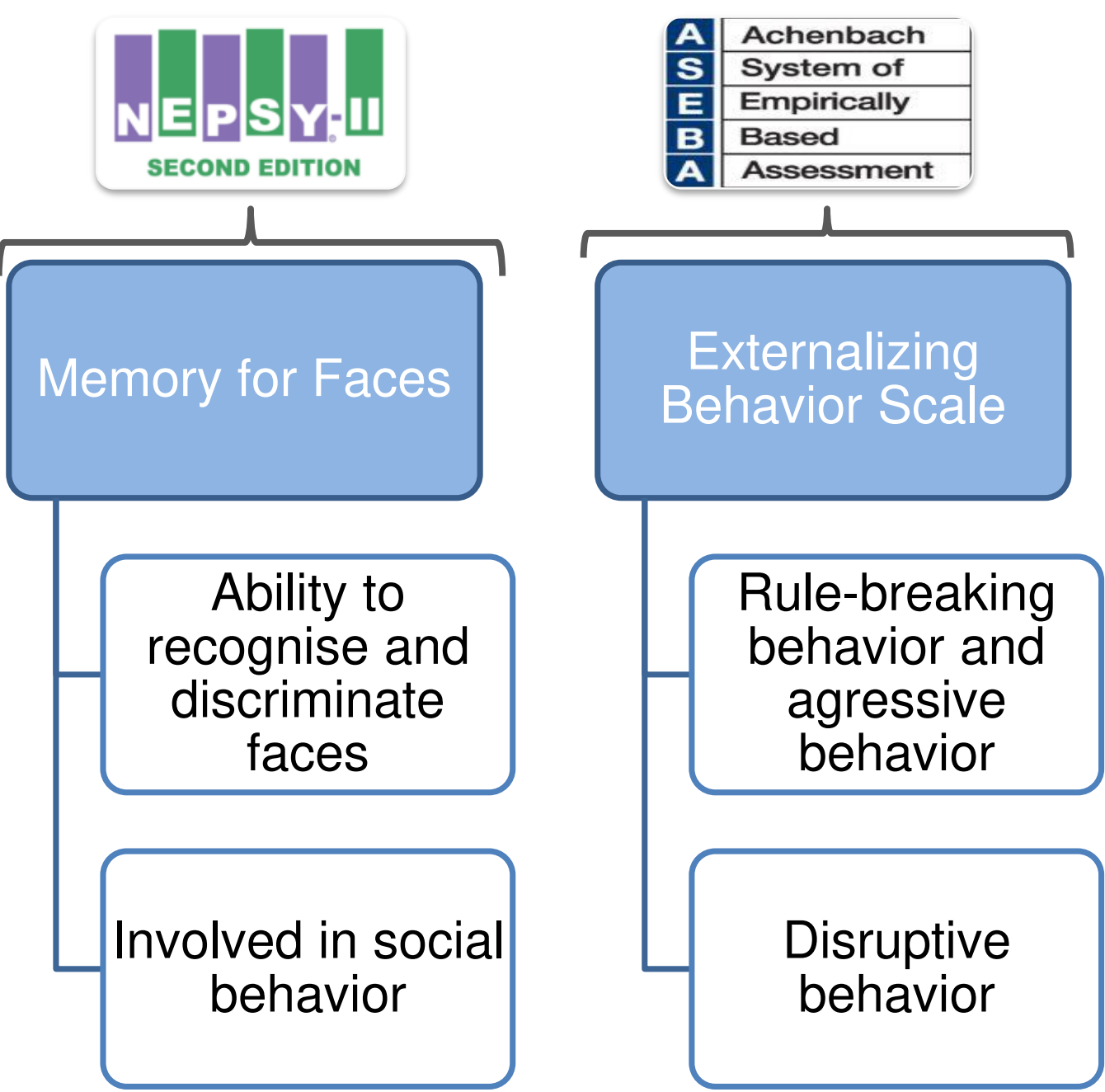

\begin{tabular}{|c|c|c|}
\hline $\begin{array}{l}\text { NEPSY-II } \\
\text { 12th month }\end{array}$ & $z$ & $\begin{array}{l}\text { Sig. Asintótica } \\
\text { (bilateral) }\end{array}$ \\
\hline Memory for Faces & -2.945 & .003 \\
\hline Delayed memory for Faces & -2.868 & .004 \\
\hline $\begin{array}{l}\text { Internalizing and } \\
\text { Externalizing Scales } \\
\text { 12th month }\end{array}$ & z & $\begin{array}{l}\text { Sig. Asintótica } \\
\text { (bilateral) }\end{array}$ \\
\hline Internalizing & -2.77 & .782 \\
\hline Externalizing & -1.999 & .046 \\
\hline
\end{tabular}

$\square$ The domains of working memory, oral comprehension, perceptive reasoning and externalizing behavior statistically improved at 12 month of treatment with Epigallocatechin Gallate $\square$ No side effects were found

$\square$ These preliminary results must be confirmed in a clinical trial controlled by placebo 